ISSN 2615-3947/P-ISSN 26I5-3947

IAIN KUDUS

O B E EDUCATION

Tersedia online: http://journal.stainkudus.ac.id/index.php/jbe

\title{
Analisis Kemampuan Technological Pedagogical and Content Knowledge Mahasiswa Calon Guru Biologi Melalui Kegiatan Presentasi di Kelas
}

\author{
Hanik Malichatin \\ IAIN Kudus \\ hanikm@iainkudus.ac.id
}

\begin{abstract}
Abstrak
Perkembangan teknologi dan komunikasi menuntut mahasiswa sebagai calon guru tidak hanya dapat menguasai materi dan cara membelajarkan siswa, namun juga menggunakan teknologi untuk memahamkan peserta didik. Artikel ini bertujuan untuk menganalisis kemampuan technological pedagogical content knowledge melalui kegiatan presentasi di dalam perkuliahan. Subyek yang digunakan dalam penelitian ini adalah mahasiswa tadris biologi yang mengikuti perkuliahan teknik dan manajemen laboratorium sebanyak 33 orang. Teknik pengumpulan data yang digunakan melalui lembar penilaian observasi kegiatan presentasi. Berdasarkan hasil dan analisis data dapat disimpulkan bhawa kemampuan technological pedagogical content and knowledge mahasiswa yang diperoleh melaluni kegiatan presentasi masih rendah. Kemampuan content knowledge dengan kategori sedang, kemampuan pedagogical knowledge dengan kategori rendah, kemampuan pedagogical content knowledge dengan kategori rendah, kemampuan technological knowledge dengan kategori tinggi dan kemampuan technological pedagogical knowledge dengan kategori sedang. Faktor yang paling mendukung kemampuan TPACK mahasiswa calon guru adalah adanya penggunaan teknologi. Hal ini disebabkan mahasiswa merupakan generasi milenial yang memiliki kemampuan cepat dalam mengikuti perubahan teknologi.
\end{abstract}

Kata kunci: $T P A C K$, calon guru, presentasi

\begin{abstract}
The development of technology and communication requires students as teacher candidates not only to master the material and how to teach students, but also to use technology to understand students. This article aims to analyze the technological pedagogical content knowledge capability through presentation activities in lectures. The subjects used in this study were tadris biology students who attended 33 engineering and laboratory management lectures. Data collection techniques used through observation observation sheet presentation activities. Based on the results and data analysis, it can be concluded that the technological capability of pedagogical content and knowledge of students obtained through presentation activities is still low. The ability of content knowledge in the medium category, the ability of pedagogical knowledge in the low category, the ability of pedagogical content knowledge in the low category, the ability of
\end{abstract}


technological knowledge in the high category and the ability of technological pedagogical knowledge in the medium category. The factor that most supports the ability of TPACK prospective teacher students is the use of technology. This is because students are millennials who have the ability to quickly follow changes in technology.

Keywords: TPACK, prospective teacher, presentation

\section{PENDAHULUAN}

Dalam dunia pendidikan guru merupakan salah satu faktor penentu keberhasilan pembelajaran. Metode pengajaran tradisional yang dilakukan oleh guru akan berpengaruh pada hasil yang diperoleh peserta didik. Guru dituntut untuk profesional tidak hanya mampu menyampaikan pengetahuan kepada peserta didik saja (transfer of knowledge) akan tetapi guru harus mampu menghubungkan peserta didik dengan sumber-sumber yang beragam baik di dalam maupu di luar sekolah. Guru dituntut pula untuk mampu mempersiapkan fasilitas pembelajaran sehingga peserta didik dapat memperoleh ketuntasan belajar yang maksimal (Huda, Sulisworo, \& Toifur, 2017). Oleh karena itu, guru diharapkan memiliki penguasaan terhadap ilmu pengetahuan dan teknologi terlebih di era revolusi industri 4.0. Hal ini menjadi tantangan dalam menyiapkan calon guru di masa yang akan datang dengan kemampuan menggunakan teknologi secara efektif (Abbitt, 2011). Penggunaan teknologi bukan hanya dalam hal kemampuan menggunakan komputer saja, tetapi pada tingkat pemahaman dan kepedulian akan informasi dan komunikasi dengan teknologi (Kozikoğlu \& Babacan, 2019). Salah satu dampak dari penggunaan ICT dalam proses pembelajaran bahwa guru harus memiliki pengetahuan dan kemampuan untuk merencanakan pembelajaran dengan baik sehingga guru tidak hanya kompeten dalam pengetahuan konten dan pedagogik saja tetapi juga kemampuan teknologinya (Oz, 2015). Menurut Koehler \& Mishra (2009) kemampuan menggunakana teknologi dengan memperhatikan aspek konten dan pedagogik disebut dengan Technological Pedagogical Content Knowledge (TPACK).

Dalam proses kegiatan belajar dan mengajar, guru juga harus dapat menyampaikan materi dengan baik karena belajar merupakan suatu proses pengembangan pengetahuan, keterampilan, dan tingkah laku yang baru pada diri seseorang sebagai hasil dari interaksinya dengan beragam informasi dan lingkungan. Oleh karena itu, mahasiswa sebagai calon guru harus diajarkan sejak dini agar dapat menyampaikan informasi yang diketahuinya dengan benar dan tepat sasaran, yaitu konten materi yang benar melalui kegiatan pedagogik yang baik agar ia menjadi calon guru yang profesional. Konten merupakan pengetahuan yang mencakup fakta, pengetahuan, prinsip, hukum dan teori serta penguasaan materi. Sedangkan pedagogik meliputi cara-cara yang dapat digunakan guru untuk membantu peserta didik memecahkan masalah pembelajaran. Pedagodik berarti pula memahami dan mengenal karakteristik dan potensi peserta didik serta mengetahui teori-teori dan prinsip-prinsip pembelajaran yang efektif (Zuhaida, 2018). 
Di era revolusi industri 4.0 ini perlu adanya pembenahan dalam pendidikan bangsa Indonesia agar dapat bersaing dengan negara-negara lain. Pembenahan ini terkait dengan kualitas dan kompetensi guru Indonesia agar tujuan pendidikan nasional dapat tercapai dengan baik. Berdasarkan kurikulum 2013, dengan dihilangkannya mata pelajaran teknologi informasi dan komunikasi (TIK) dan menjadikan TIK sebagai salah satu media dalam proses pembelajaran. Hal ini menuntut guru untuk mampu menggunakan teknologi dalam setiap proses pembelajaran. Oleh karena itu, mahasiswa calon guru harus mampu menguasai teknologi tersebut. Penggunaan teknologi didalam proses pembelajaran bukanlah hal yang mudah terlebih bagi calon guru. Seorang calon guru harus mampu menguasai materi yang akan diajarkan (Sholihah, Yuliati, \& Wartono, 2016) supaya dapat menentukan teknologi yang tepat. Penguasaan materi dapat dilakukan dengan menganalisis karakteristik materi tersebut sehingga strategi pembelajaran yang sesuai pun akan digunakan sesuai dengan teknologi yang dipilih.

Jadi, bagi calon guru biologi supaya dapat melaksanakan pembelajaran dengan baik maka diperlukan kemampuan menguasai materi, pedagogik dan teknologi. Integrasi dari kemampuan tersebut terbentuklah Technological Pedagogical and Content Knowledge (TPACK). Technological Pedagogigal Content and Knowledge (TPACK) terdiri atas tiga komponen utama yaitu pengetahuan konten (content knowledge), pengetahuan pedagogik (pedagogigal knowledge) dan pengetahuan teknologi (technological knowledge) (Chai \& Koh, 2017; Koehler \& Mishra, 2009; Oz, 2015). Perpaduan antara ketiga komponen tersebut membentuk PCK (pedagogical Content Knowledge), TCK (Technological Content Knowledge) dan TPK (Technological Content Knowledge) serta TPACK (Technological Pedagogical Content and Knowledge). Pengertian dari masing-masing komponen dapat dijelaskan sebagai berikut :

1. Content knowledge (CK) adalah pengetahuan tentang materi subyek yang akan diajarkan $(\mathrm{Oz}, 2015)$;

2. Pedagogical knowledge (PK) adalah pengetahuan tentang, proses, praktik dan metode dalam pembelajaran. Dengan kata lain, pengetahuan pedagogik adalah pemahaman yang harus dimiliki oleh guru tentang metode, teknik, manajemen kelas dan pendekatan dalam proses pembelajaran.

3. Technological knowledge (TK) adalah pengetahuan tentang berbagai teknologi digital seperti komputer, internet, digital video, aplikasi software atau kemampuan untuk mengadaptasi dan mempelajari teknologi baru.

4. Pedagogical content knowledge (PCK) adalah hubungan antara pengetahuan dasar dari konten dan pedagogi yang diterapkan guru di dalam kelas.

5. Technological content knowledge (TCK) menjelaskan hubungan antara teknologi dan konten materi. Pengetahuan yang baik tentang teknologi akan berdampak baik pada kemampuan untuk menyampaikan materi dengan baik sehingga mudah dipahami. Selain itu pula, dengan kemampuan ini guru akan mampu menentukan media yang tepat untuk menyampaikan materi yang akan diajarkan (Rosyid, n.d.).

6. Technological Pedagogical Knowledge (TPK) yaitu kemampuan yang menyatakan hubungan timbal balik antara teknologi dan pedagogik. Dengan adanya kemampuan ini memungkinkan calon guru untuk menggunakan teknologi guna mencapai tujuan 
pedagogik. Dengan menggunakan teknologi akan memudahkan guru untuk menciptakan metode baru di kelas.

7. Technological Pedagogical Content And Knowledge (TPACK) yaitu pengetahuan yang merupakan perpaduan dari setiap bidang pengetahuan (content knowledge, pedagogical knowledge, technological knowledge, pedagogigal content knowledge, dan technological content knowledge) dengan memfokuskan pada penggunaan teknologi untuk mengajarkan konten dan mencapai tujuan pedagogik.

Kerangka umum dari komponen TPACK tersebut digambarkan seperti pada gambar 1.

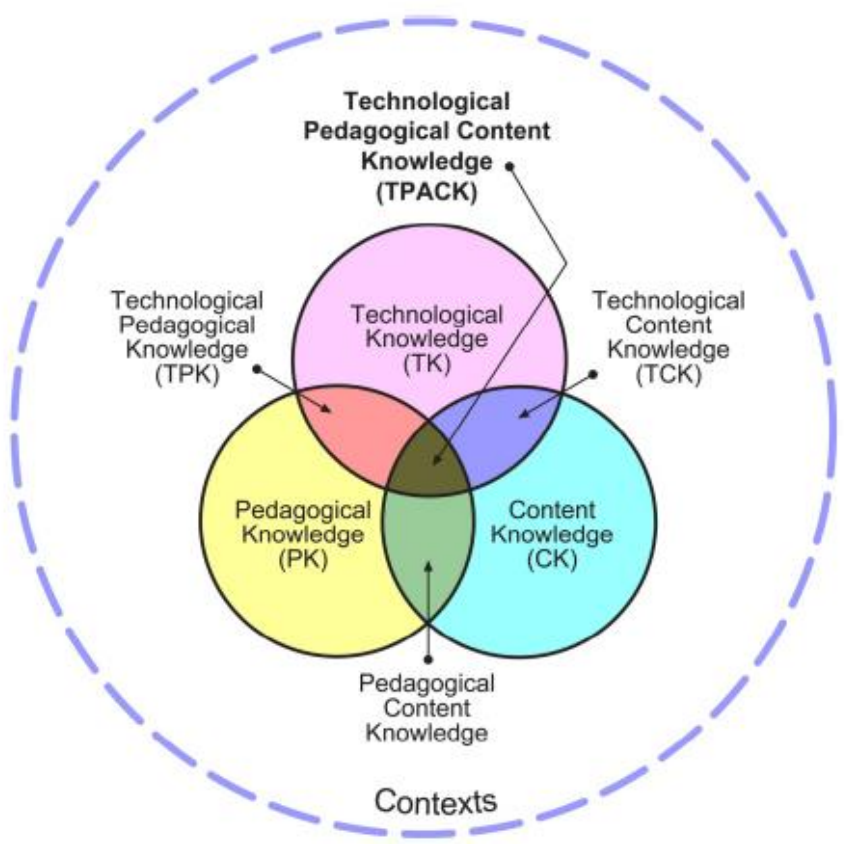

Gambar 1. Kerangka kerja kompone TPACK (Koehler \& Mishra, 2009)

Kerangka TPACK seperti pada Gambar 1 dapat dijadikan sebagai kerangka teori dan konsep dalam mengukur kesiapan calon guru dan guru dalam proses pembelajaran di kelas secara efektif menggunakan teknologi terlebih pada era revolusi industri sekarang. Revolusi industri 4.0 dan pemberlakuan kurikulum 2013 yang secara implisit mengharuskan guru untuk menggunakan teknologi serta pendekatan active learning dalam proses pembelajaran. Untuk itu guru dituntut dapat memilih metode yang tepat untuk menyampaikan materi kepada peserta didik sesuai dengan konten dan karakter peserta didik. Salah satu metode yang dapat digunakan adalah metode presentasi.

Presentasi merupakan kegiatan komunikasi yang dapat membuat orang berpikir logis, tepat dan memiliki pendapat ((Hernawati \& Amin, 2017). Seorang presenter yang baik akan mampu memahamkan audiens. Kemampuan presenter untuk memahamkan terseburt sebagai salah satu bukti adanya pemahaman pedagogil yang dimiliki oleh 
presenter dalam hal ini adalah calon guru. Dalam perkuliaahan presentasi merupakan salah satu tugas yang diberikan untuk membantu meningkatkan kemampuan berkomunikasi mahasiswa dan menyampaikan gagasan yang dimiliki di depan umum. Hanya saja tidak semua mahasiswa mampu melaksanakan tugas presentasi dengan baik.

Berdasarkan hasil observasi lapangan diperoleh beberapa permasalahan terkait dengan kemampuan mahasiswa antara lain mahasiswa belum seluruhnya menggunakan powerpoint dalam presentasi tugas mata kuliah, materi presentasi yang dibuat bukan hanya poin saja melainkan menyalin seluruh isi dari tugas atau artikel, mahasiswa kurang menguasai materi yang disampaikan. Permasalahan lain yang ditemukan adalah mahasiswa calon guru masih lemah dalam mengaitkan materi dengan teknologi yang ada. Berdasarkan latar belakang tersebut maka artikel ini bertujuan untuk menganalisis lebih mendalam tentang kemampuan TPACK mahasiswa calon guru melalui kegiatan presentasi yang dilakukan selama perkuliahan.

\section{METODE PENELITIAN}

Penelitian ini menggunakan metode deskriptif kualitatif. Subjek penelitian yang digunakan berjumlah 33 mahasiswa tadris biologi yang mengikuti mata kuliah teknik dan manajemen laboratorium. Teknik pengambilan sampel dengan menggunakan teknik sampel jenuh. Semua populasi dijadikan sampel penelitian. Instrumen penelitian yang digunakan berupa lembar penilaian presentasi yang digunakan selama perkuliahan dan lembar observasi. Analisis dan observasi dilakukan difokuskan pada pengembangan kemampuan mahasiswa calon guru dalam Technological Pedagogical and Content Knowledge.

\section{HASIL DAN PEMBAHASAN}

\section{Kemampuan Presentasi Mahasiswa}

Berdasarkan hasil penilaian terhadap mahasiswa calon guru biologi pada mata kuliah teknik dan manajemen laboratorium ketika melakukan presentasi diperoleh data seperti Tabel 1.

Tabel 1. Komponen penilaian presentasi

\begin{tabular}{lcc}
\hline Komponen penilaian presentasi & Skor & Kriteria \\
\hline 1. Materi Presentasi & & \\
a. Desain Slide & 80,6 & Sedang \\
b. Urutan Slide & 83,6 & Tinggi \\
c. Ukuran Huruf & 77,0 & Rendah \\
d. Kesesuaian gambar & 81,2 & Sedang \\
e. Kontras warna & 86,7 & Tinggi \\
\hline
\end{tabular}


2. Cara penyampaian materi
a. Suara
80,0 Rendah
b. Kepercayaan diri
77,6 Rendah
c. Ekspresi
78,8 Rendah
d. Kelancaran
81,2 Sedang

3. Penguasaan Materi
a. Menunjukkan penguasaan materi
82,6 Sedang

b. Mengaitkan materi dengan pengetahuan lain yang relevan

c. Menyampaikan materi dengan jelas sesuai hirarki belajar

79,7 Rendah

$81,2 \quad$ Sedang

4. Strategi Pembelajaran
a. Menguasai kelas
76,5 Rendah
b. Melaksanakan pembelajaran yang bersifat positif

78,4 Rendah

Setiap komponen diberi skor dengan rentang $5=$ sangat baik; $4=$ baik; $3=$ cukup baik; 2 = kurang baik; dan 1 = tidak baik. Langkah berikutnya skor yang diperoleh mahasiswa calon guru kemudian diolah dengan rumus:

$$
\text { Nilai }=\frac{\text { skor yang diperoleh mahasiswa }}{\text { skor maksimal }} \times 100
$$

Skor yang diperoleh tersebut kemudian dikelompokkan menjadi kategori technological pedagogical and content knowledge seperti pada Tabel 2.

\begin{tabular}{cc} 
Tabel 2. Kriteria Penilaian skor TPACK \\
\hline Rentang & Kriteria \\
\hline Nilai $\geq \overline{\boldsymbol{x}}+\boldsymbol{S D}$ & Tinggi \\
\hline$\overline{\boldsymbol{x}}-\boldsymbol{S D} \leq \boldsymbol{n i l a i}<\overline{\boldsymbol{x}}+\boldsymbol{S D}$ & Sedang \\
\hline $\boldsymbol{N i l a i} \leq \overline{\boldsymbol{x}}-\boldsymbol{S D}$ & Rendah
\end{tabular}

Sumber: (Listiawan \& Widyo Baskoro, 2015)

Berdasarkan Tabel 1 diketahui bahwa mahasiswa sudah cukup mampu menggunakan teknologi dalam proses pembelajaran dalam hal ini melalui kegiatan presentasi yang dilakukan oleh mahasiswa. Kemampuan mahasiswa dalam membuat urutan materi yang ditampilkan dalam slide termasuk dalam kriteria tinggi. Ini berarti mahasiswa sebagai calon guru mampu menyusun urutan materi sesuai dengan tingkat kesulitan dengan baik. Selain itu pula, dari segi tampilan atau desain slide sudah baik. Akan tetapi dalam hal penyampaian materi masih dalam kategori rendah. Proses 
penyampaian materi tidak terlepas dari kemampuan mahasiswa dalam berkomunikasi dan pemahaman mahasiswa terhadap materi yang disampaikannya. Hal ini sesuai dengan pernyataan Joyce et al (2000) bahwa kemampuan mahasiswa dalam berkomunikasi ilmiah berhubungan positif dengan pemahaman konsep yang dimilikinya. Presentasi merupakan salah satu bentuk komunikasi yang dilakukan baik dengan suara, gambar maupun bahasa tubuh. Presentasi yang dikatakan berhasil apabila audien dapat memahami pesan yang disampaikan pemateri sesuai dengan yang diharapkan pemateri. Hal ini akan terjadi jika pemateri menggunakan media yang tepat, bahasa yang tepat dan waktu yan tepat ketika melakukan presentasi (Hernawati \& Amin, 2017). Selain itu, melalui presentasi dapat diketahui pula kemampuan presenter dalam hal ini mahasiswa.

Berdasarkan Tabel 1 dapat diuraikan kemampuan TPACK mahasiswa calon guru sebagai berikut :

a. Kemampuan Content Knowledge (CK)

Kemampuan content knowledge diteliti dari keluasan materi, kedalaman materi, kesesuaian materi dan pengembangan materi. Penguasaan materi mahasiswa rata-rata dengan kategori sedang. Mereka mampu menjelaskan yang diajarkan dengan cukup baik. Hany saja dalam mengaitkan materi dengan materi lain yang relevan masih kurang atau mahasiswa kurang mampu menjabarkan materi yang dipresentasikan dan memberikan informasi terbaru terkait materi. Hal ini disebabkan mahasiswa hanya menggunakan buku pegangan sebagai satu-satunya sumber untuk membuat materi presentasi.

\section{b. Kemampuan Pedagogical Knowledge (PK)}

Kemampuan pedagogical knowledge terkait dengan strategi yang digunakan oleh mahasiswa dalam melakukan presentasi. Kemampuan ini termasuk dalam kategori rendah. Secara umum mahasiswa belum mampu menghidupkan suasana kelas ketika proses pembelajaran berlangsung. Proses diskusi ketika pembelajaran berlangsung belum sepenuhnya berjalan dua arah. Selain itu, mahasiswa yang terpilih sebagai presenter rata-rata masih membaca tulisan yang ada di powerpoint. Hal ini juga didukung oleh skor kepercayaan diri mahasiswa yang masih rendah. Rendahnya nilai kepercayaan diri mahasiswa ini berkaitan dengan kemampuan pengelolaan diri. Ketika melakukan presentasi, mahasiswa lebih fokus pada pengendalian diri agar dapat menyampaikan materi dengan baik sehingga kurang memperhatikan cara menyampaikan materi yang baik kepada audien (Sukaesih, Ridlo, \& Saptono, 2017).

\section{c. Kemampuan Pedagogical Content Knowledge (PCK)}

Kemampuan PCK terkait dengan kemampuan mahasiswa dalam memilih strategi untuk menjelaskan konten materi yang diajarkan. Berdasarkan tabel 1 kemampuan PCK mahasiswa masih dalam kategori rendah. Ketika melakukan presentasi mahasiswa belum sepenuhnya mampu menggunakan strategi presentasi untuk menjelaskan materi dengan baik. Hal ini terlihat ketika proses presentasi berlangsung umumnya mahasiswa masih fokus pada tampilan powerpoin tanpa 
memperhatikan audien. Selain itu, kondisi kelas yang terkadang ramai tidak diperhatikan oleh presenter.

\section{d. Kemampuan Technological Knowledge (TK)}

Kemampuan menggunakan teknologi mahasiswa dapat dikatakan baik atau dalam kategori tinggi. Kemampuan ini terlihat pada kemampuan mahasiswa dalam membuat slide powerpoin dengan desain yang menarik, kontras warna yang bagus dan urutan silde sesuai dengan urutan materi yang tepat. Akan tetapi, konten materi yang dituliskan dalam slide powerpoin masih kurang karena umumnya mahasiswa masih meng-copy paste materi dari bahan ajar bukan berupa poin-poin penting dari materi yang akan disampaikan.

Kemampuan TK ini juga terlihat dari adanya video atau animasi pendukung yang digunakan untuk membantu memperjelas materi.

\section{e. Kemampuan Technological Content Knowledge (TCK)}

Dari hasil analisis penilaian presentasi, kemampuan TCK mahasiswa kategori sedang. Mahasiswa mampu menggunakan teknologi untuk menyampaikan materi. Akan tetapi beberapa mahasiswa ketika menjelaskan materi presentasi mengabaikan tampilan powepoin yang telah dibuat. Mahasiswa justru membaca dari buku yang dibawa.

\section{f. Kemampuan Technological Pedagogical Knowledge (TPK)}

Ketrampilan TPK terkait dengan pengintegrasian teknologi dengan strategi yang digunakan. Secara umum kemampuan TPK ini sudah cukup baik hanya saja berdasarkan hasil analisis dan pengamatan di lapangan ditemukan beberapa mahasiswa belum mampu mengintegrasikan teknologi dengan strategi yang sesuai. Hal ini terlihat dari pemanfaatan media powerpoin yang digunakan belum maksimal.

\section{g. Kemampuan Technological Pedagogical Content and Knowledge}

Secara umum kemampuan TPACK mahasiswa calon guru dikatakan cukup baik atau dengan kategori rendah. Hal ini terlihat dari skor aspek penilaian presentasi rata-rata berada pada kategori rendah. Kemampuan TPACK mahasiswa calon guru dipengaruhi oleh beberapa faktor antara lain usia, kebiasaan menggunakan teknologi dalam kehidupan sehari-hari, kebiasaan menggunakan teknologi dalam pembelajaran. Mahasiswa adalah orang-orang yang berada pada generasi milenial. Umumnya generasi milenial memiliki kemampuan yang cepat dalam mengikuti perubahan teknologi. Hal ini yang menjadikan kemampuan TK dan TPK mahasiswa tinggi.

Profil TPACK mahasiswa menjadi suatu hal yang penting karena dapat dijadikan sebagai gambaran awal kemampuan pedagogik, peguasaan materi (konten) dan teknologi calon guru sebelum melaksakan pembelajaran yang nyata di sekolah. Selain itu, hasil analisis TPACK ini dapat dijadikan sebagi bahan evaluasi perkuliahan untuk dilakukan perbaikan. Kemampuan ini juga dapat digunakan sebagai bahan informasi terkait 
kemampuan guru yang unggul atau kemampuan guru yang dibutuhkan di masa yang akan datang.

\section{KESIMPULAN}

Berdasarkan hasil dan analisis data dapat disimpulkan bhawa kemampuan technological pedagogical content and knowledge mahasiswa yang diperoleh melaluni kegiatan presentasi masih rendah. Kemampuan content knowledge dengan kategori sedang, kemampuan pedagogical knowledge dengan kategori rendah, kemampuan pedagogical content knowledge dengan kategori rendah, kemampuan technological knowledge dengan kategori tinggi dan kemampuan technological pedagogical knowledge dengan kategori sedang.

Faktor yang paling mendukung kemampuan TPACK mahasiswa calon guru adalah adanya penggunaan teknologi. Hal ini disebabkan mahasiswa merupakan generasi milenial yang memiliki kemampuan cepat dalam mengikuti perubahan teknologi.

\section{Referensi}

Abbitt, J. T. (2011). An Investigation of the Relationship between Self-Efficacy Beliefs about Technology Integration and Technological Pedagogical Content Knowledge (TPACK) among Preservice Teachers. Journal of Digital Learning in Teacher Education, 27(4), 134-143.

Chai, C. S., \& Koh, J. H. L. (2017). Changing teachers' TPACK and design beliefs through the Scaffolded TPACK Lesson Design Model (STLDM). Learning: $\begin{array}{llll}\text { Research } \quad \text { and } & \text { Practice, } & \text { 114-129. }\end{array}$ https://doi.org/10.1080/23735082.2017.1360506

Hernawati, D., \& Amin, M. (2017). Analisis Self Efficacy Mahasiswa Melalui Kemampuan Presentasi Di Kelas.

Huda, C., Sulisworo, D., \& Toifur, M. (2017). Analisis Buku Ajar Termodinamika dengan Konsep Technological Pedagogical and Content Knowledge (TPACK) untuk Penguatan Kompetensi Belajar Mahasiswa. Jurnal Penelitian Pembelajaran Fisika, $8(1)$.

Joyce, B., Weil, M., \& Calhoun, E. (2000). Models of Teaching (Sixth Edit). Boston: Allyn and Bacon.

Koehler, M. J., \& Mishra, P. (2009). What is technological pedagogical content knowledge? Contemporary Issues in Technology and Teacher Education (Vol. 9). Retrieved from http://www.tpck.org/.

Kozikoğlu, İ., \& Babacan, N. (2019). The investigation of the relationship between Turkish EFL teachers' technological pedagogical content knowledge skills and attitudes towards technology. Journal of Language and Linguistic Studies, 15(1), 20-33. https://doi.org/10.17263/jlls.547594

Listiawan, T., \& Widyo Baskoro, W. (2015). Analisis Technological Content Knowledge 
(TCK) Calon Guru Matematika Dalam Menggunakan Perangkat Lunak Geometri Dinamis.

Oz, H. (2015). Assesing pre service english as a foreign Language teachres' technological pedagogical content knowledge. International Education Studies, 8(5), 119-130.

Rosyid, A. (n.d.). Technological Pedagogical Content Knowledge: Sebuah Kerangka Pengetahuan Bagi Guru Indonesia di Era MEA. Prosiding Seminar Nasional Inovasi Pendidikan Inovasi Pembelajaran Berbasis Karakter Dalam Menghadapi Masyarakat Ekonomi ASEAN, 446-454.

Sholihah, M., Yuliati, L., \& Wartono, W. (2016). Peranan TPACK Terhadap Kemampuan Menyusun Perangkat Pembelajaran Calon Guru Fisika Dalam Pembelajaran Post-Track. Jurnal Pendidikan: Teori, Penelitian Dan Pengembangan, 1(2), 144-153.

Sukaesih, S., Ridlo, S., \& Saptono, S. (2017). ANALISIS KEMAMPUAN TECHNOLOGICAL PEDAGOGICAL AND CONTENT KNOWLEDGE (TPACK) CALON GURU PADA MATA KULIAH PP BIO. Seminar Nasional Pendidikan Sains "Strategi Pengembangan Pembelajaran Dan Penelitian Sains Untuk Ketrampilan Abad 21, " 58-64.

Zuhaida, A. (2018). Penyusunan Instrumen Analisis Pedagogical Content Knowledge Guru IPA Madrasah Tsanawiyah Terintegrasi Konten Islami. Edukasia Islamika: Jurnal Pendidikan Islam, 3(2), 234-248. https://doi.org/https://doi.org/10.289.18/jei/v3i2.1690 